\title{
Estimation of fetal age sonographically using umbilical cord diameter in second and third trimester
}

\author{
Elsafi Ahmed Abdalla, Caroline Edward Ayad", Farida Ahmed Eisa \\ Ultrasound Department College of Medical Radiological Science, Sudan University of Science and Technology, Khartoum, Sudan \\ Email address: \\ dr.elsafi@gmail.com (E. A. Abdalla),dr.elsafi@sustech.edu (E. A. Abdalla), carolineayad@yahoo.com (C. E. Ayad), \\ carolineayad@sustech.edu (C.E.Ayad), faridaessa@yahoo.com (F. A. Eisa)
}

\section{To cite this article:}

Elsafi Ahmed Abdalla, Caroline Edward Ayad, Farida Ahmed Eisa. Estimation of Fetal Age Sonographically Using Umbilical Cord Diameter in Second and Third Trimester. American Journal of Health Research. Vol. 2, No. 2, 2014, pp. 68-72.

doi: 10.11648/j.ajhr.20140202.16

\begin{abstract}
Assessment of gestational age is paramount in obstetric care. This study was to evaluate the gestational age (GA) by measuring the Umbilical Cord Diameter (UCD) in the second and third trimester of pregnancy, and to compare the findings with the Femur Length (FL), Bi- parietal Diameter (BPD) and Last Menstrual Period (LMP). Fifty Sudanese Pregnant women underwent routine sonographic examination using $3.5 \mathrm{MHz}$ curve liner transducer; the sonographic cross-sectional area of the umbilical cord was measured in a plane adjacent to the insertion of the cord into the fetal abdomen. Maternal age and number of parity have been evaluated. The relation was statistically significant between UCD depth, width and GA. Gestational age can be predicted and can be depicted by the following equations: GA= $(1.380 \times \mathrm{UCD}$ length +8.160$)$ and $\mathrm{GA}=(1.545 \times \mathrm{UCD}$ width +5.943$)$. There was unsubstantial relation between UCD and maternal age. A linear relationship was found between parity and the UCD depth and width. Using paired T-test indicates that the GAs calculated from FL was accurate, there was no significant difference detected between the LMP age and the estimated one and UCD depth, width, but BPD showed significant difference at $p=0.005$.Measuring UCD is useful for the assessment of gestational age. It has a role in obstetric care in the second and third trimester of pregnancy, and these equations can be used to estimate the gestational age instead of BPD and FL.
\end{abstract}

Keywords: Gestation Age, Umbilical Cord, Ultrasound

\section{Introduction}

The umbilical cord is one of the fetal organs always visible by ultrasound examination in the first trimester of pregnancy; sonographic studies on the morphometry of the umbilical cord at this gestational age are very little.[1-3] Evaluation of umbilical cord morphology was restricted to the post-partum period and was performed to explain that a thin umbilical cord was associated with adverse pregnancy outcome.[4,5] Accurate estimation of fetal age is important for appropriate antennal management. The estimation of gestational age by ultrasounography is based on the known relationship between fetal age and size. [6, 7, 8] A significant correlation between the sonographic umbilical cord length and either gestational age or crown-rump length (CRL) in the first trimester of gestation has been reported [9]. The sonographic size of the umbilical cord in the first trimester is related to fetal growth during the pregnancy; studies have reported that an altered morphology of the umbilical cord in the second and third trimesters of pregnancy is associated with adverse pregnancy outcome, intra partum complications and altered umbilical vein blood flow. [10-13] Problems affected umbilical cord in the second half of pregnancy puts the fetus at increased risk of being small-for-gestational age and of having signs of distress at delivery $[10,14,15]$ Accurate pregnancy dating assist obstetricians in appropriately counselling women who are at risk of a preterm delivery. Accurate gestational age assessment is essential in the evaluation of fetal growth and detection of intrauterine growth restriction and counselling patients regarding the selection of pregnancy termination. [16] Sonographic gestational age assessment is of clinical value in screening for fetal anomalies, in that it has been shown to decrease the incidence of post-term and preterm diagnoses.[17,18]Uncertain gestational age has been associated with higher perinatal mortality rates and an increase of low birth weight and spontaneous preterm delivery. [19]Ultrasound assessment of gestational age is of 
greater accuracy than physical examination. In the first trimester, gestational sac mean diameter and crown-rump length measurements have become the primary means of evaluating gestational age. $[20,21]$ In the second and third trimesters, fetal head, body, and extremity measurements have been commonly used to assess gestational age. The most common measured parameters are biparietal diameter, [22, 23] head circumferences, [24] abdominal circumference, [25] and femur length. [26] Other parameters were also used for gestational age assessment. [27]

Accurate gestational age assessment is of great importance in obstetric practice. Appropriate estimation of gestational age requires good judgment by the obstetrician caring for the patient. This study was obtained to estimate the fetal age using umbilical cord diameter in the second and third trimesters of gestation and to investigate whether the sonographic measurement of the umbilical cord has clinical value in obstetric field.

\section{Materials and Methods}

The study was done at El-Rabat Hospital, Ultrasound Department in the period from December 2011 to February 2012.

\subsection{Machine used and Inclusion Criteria}

Ultrasound Machine used was Siemens-SONOLINE G60S fitted with a (3.5) $\mathrm{MHz}$ curve liner transducer. Fifty Sudanese pregnant women in their second and third trimester were included; their ages were between 18 and 47 years old with known LMP date and with different number of parity. Maternal with fetal anomaly, chronic disease, multiple pregnancies, unknown date of LMP, polyhydramniuos and olygohydramniuos were excluded.

\subsection{Methods}

Women were asked about their pregnancies by identifying and reporting the first day of their last menstrual period. The BPD was measured from the maximum diameter of a transverse section of the fetal skull at the level of the parietal eminences .Transverse section of the fetal head used for measuring the BPD was the thalami view. Measuring the femoral length was done by sliding the probe caudally until the iliac bones were visualized. At this point of view, a cross-section of one or both femurs is usually seen. The upper femur was selected for measurement. Keeping the echo from the anterior femur in view, the probe was rotated until the full length of the femur was obtained. Full length of the femur was detected. The femur length is the distance between the caliper markers. Trans abdominal scan with patient supine was done, The UCD1 and UCD2 was measured cross sectionally in a plane adjacent to the insertion of the cord into the fetal abdomen with the calipers placed outer to-outer. Two measurements were taken in two different images in millimeters. The data were collected using the variables age, parity, LMP, BPD, FL and UCD1 and UCD 2. The data were analyzed by using Statistical Package For Social Sciences (SPSS) software and Excel programs, where scatter plot showed the linear relationship between the UCD and LMP as well as T-test to test the significances between the gestational age for LMP and the one that estimated by UCD1 and UCD2, PBD and FL. The Ethics and Research Committee approved the study, and informed consent was obtained from all participants.

\section{Results}

Fifty pregnant ladies in the second and third trimester were enrolled, their ages were between 18 and 47 years old, BPD, FL and two diameters of UCD were measured and compared to GA by LMP.

Table 1. Shows the relation between maternal age group and mean UCDs the result was $U C D$ increase by $0.02 \mathrm{~mm} / 10 \mathrm{yrs}$.

\begin{tabular}{ccc}
\hline Age group/ yrs & Mean UCD1/mm & Mean UCD2/mm \\
\hline $18-27$ & 11.39 & 13.17 \\
$28-37$ & 12.59 & 14 \\
$38-47$ & 11.33 & 12.3 \\
\hline
\end{tabular}

Yrs =years, $\mathrm{UCD}=$ umbilical cord diameter, $\mathrm{Mm}=$ millimetre $\mathrm{UCD} 1=$ depth, $\mathrm{UCD} 2=$ Width the results show the relation between maternal age group and mean UCDs the result was UCD increase by $0.02 \mathrm{~mm} / 10 \mathrm{yrs}$.

Table 2. Shows the relation between numbers of parity and mean $U C D$ s. The result was $U C D$ increase by $0.55 \mathrm{~mm} / 2$ parity and $0.5 \mathrm{~mm} / 2$ parity respectively.

\begin{tabular}{ccc}
\hline Parity & Mean UCD 1 & Mean UCD 2 \\
\hline 0 & 10.0 & 11.9 \\
1 & 11.4 & 13.4 \\
2 & 12.0 & 13.6 \\
3 & 12.0 & 14.0 \\
4 & 11.4 & 13.2 \\
5 & 13.7 & 14.7 \\
6 & 12.5 & 14.0 \\
8 & 12.0 & 13.3 \\
9 & 18.0 & 18.0 \\
\hline
\end{tabular}

Table 3. Shows the relation between GA by LMP and other parameters there is strong correlation between GA by LMP, FL, BPD and UCDs

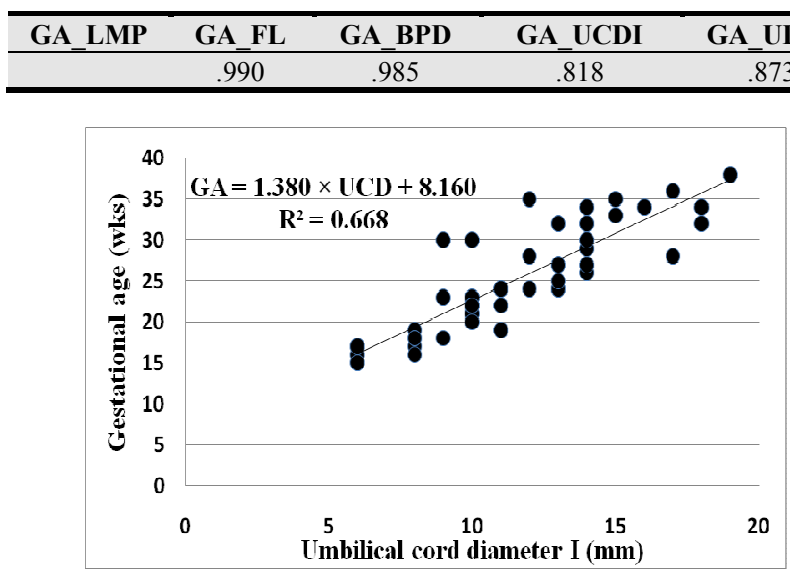

Fig 1. scatter plot of the UCD1 verse the LMP gestational age with a trend line shows a direct linear relationship GA increaseby1.4/5mm with $R 2=0.668$. 


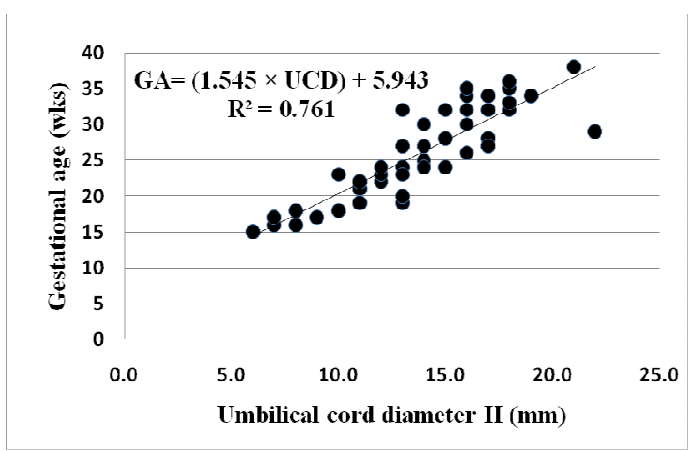

Fig 2. scatter plot of the UCD2 verse the LMP gestational age with a trend line shows a direct linear relationship, GA increase by $1.5 / 5 \mathrm{~mm}$ with $R 2=0.761$.

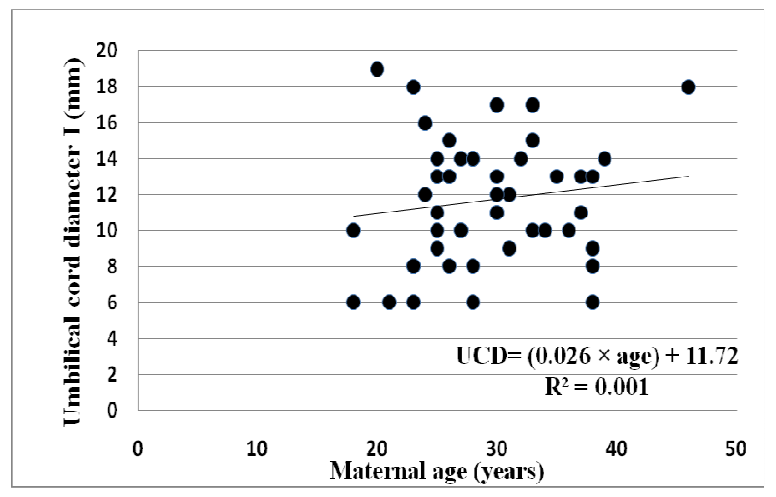

Fig 3. Scatter plot of the UCD1 verse the maternal age with a trend line shows a direct linear relationship UCD increase by $0.02 \mathrm{~mm} / 10$ years.

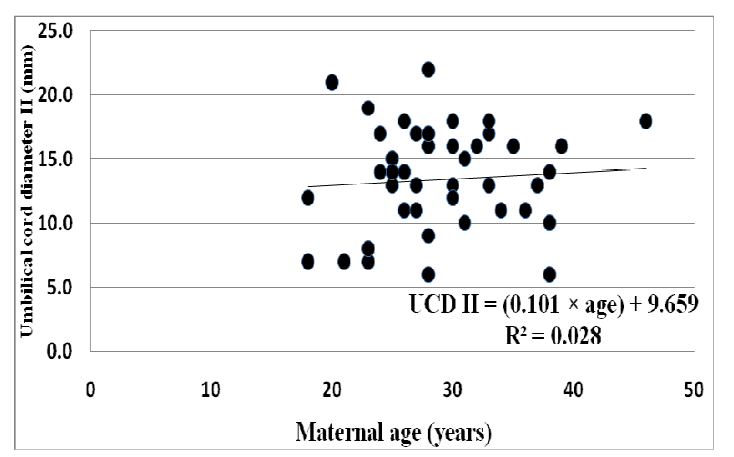

Fig 4. Scatter plot of the UCD2 verse the maternal age with a trend line shows a direct linear relationship UCD increase by $0.1 \mathrm{~mm} / 10$ years with $R 2=0.028$

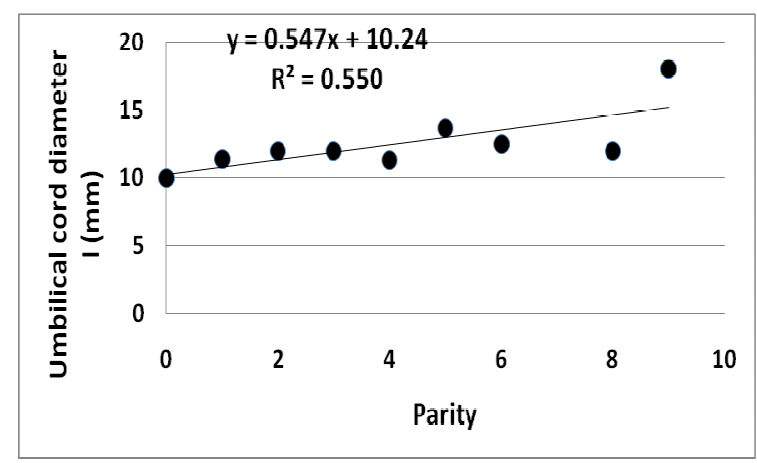

Fig 5. Scatter plot of the UCD1 verse the number of parity with a trend line show a direct linear relationship UCD increase by $0.5 \mathrm{~mm} / 2$ parity with $R 2=0.550$

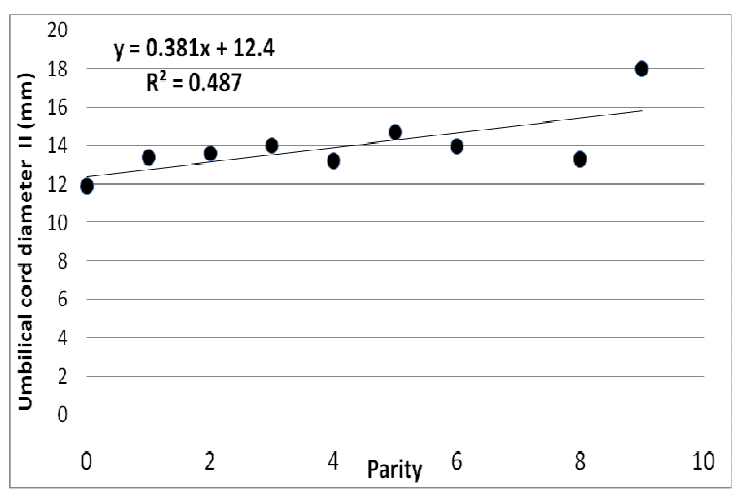

Fig 6. Scatter plot of the UCD2 verse the number of parity with a trend line show a direct linear relationship UCD increase by $0.4 \mathrm{~mm} / 2$ parity.

Table 4. Shows T value and P value: and GA by FL, BPD and both UCD. T value and $P$ value: $B P D$ shows significant difference at $p=0.005$ with $t$ $=2.93$. No significant difference between GA by LMP and GA by FL, both $U C D$.

\begin{tabular}{lll}
\hline & T-Test & P-value \\
\hline GA_LMP - GA_FL & .629 & .533 \\
GA_LMP - GA_BPD & 2.929 & .005 \\
GA_LMP - GA_UCD1 & .019 & .985 \\
GA_LMP - GA_UDC2 & .023 & .982 \\
\hline
\end{tabular}

$\mathrm{GA}=$ Gestational age, LMP $=$ Last menstrual period, $\mathrm{FL}=\mathrm{Femur}$ Length, $\mathrm{BPD}=$ Biparital Diameter, Umbilical cord Diameter $=\mathrm{UCD}$ including (UCD1= depth, $\mathrm{UCD} 2=$ Width)

\section{Discussion}

This study was conducted to assess the gestation age by fetal umbilical cord diameter (UCD) using ultrasound. Table (1) and table (2) presented the age classes, parity and mean values of UCD1 and UCD2 respectively. The gestational age by last menstrual Period (LMP) in weeks was compared to $\mathrm{UCD} 1, \mathrm{UCD} 2$ as shown in table (3). It was found that the relation was statistically significant between UCD1and GA and by using linear regression ;it was found that there was a direct proportionality linear relationship which can be depicted by the following equations: $\mathrm{GA}=(1.380 \times \mathrm{UCD} 1)$ +8.160 and the correlation coefficient $r=0.82$ (Fig 1). There was also found statistically significant relationship between $\mathrm{UCD} 2$ and GA using the equation as: $\mathrm{GA}=(1.545 \times \mathrm{UCD} 2$ +5.943 ). $\mathrm{r}=0.761$ (Fig 2). These equations can be used to estimate the gestational age instead of BPD and FL. The relation between the UCD depth, width versus maternal age were studied, the results showed that there was un substantial relation between UCD1 versus the maternal age; the UCD1 increase by $0.02 \mathrm{~mm} / 10$ years, insignificant relation between age with $\mathrm{UCD} 1$ at $p=0.05$ with $\mathrm{r}=0.03$, and $\mathrm{UCD} 2$ verse the maternal age showed that UCD2 increase by $0.1 \mathrm{~mm} / 10$ years with $\mathrm{r}=0.03$. (Fig3and4)when using the equations:

$$
\begin{aligned}
& \{\mathrm{UCD} 1=(0.026 \mathrm{X} \text { Maternal age })+11.72\} \\
& \{\mathrm{UCD} 2=(0.101 \mathrm{X} \text { Maternal age })+9.659\}
\end{aligned}
$$

The diameter as depth and width can be estimated. The results also showed that there was a direct linear relation of the parity with the UCD where in case of the depth it 
increased by $0.55 \mathrm{~mm} / 2$ parity(Fig 5) and the width by 0.5 $\mathrm{mm} / 2$ parity(Fig 6) with a significant relation at $p=0.05$ with a correlation coefficient equal to 0.78 and 0.71 respectively .Using paired t-test indicated that the GAs calculated from FL were accurate and there was no significant difference at $p=0.05$ detected between the LMP age and that estimated with FL, $\mathrm{t}=0.63$ and $p=0.53$ as well as the UCD1, UCD2 with $\mathrm{t}=0.02$ for both , and $p=0.9$ but BPD showed significant difference at $p=0.005$ with $\mathrm{t}=2.93$ (Table 4). The accuracy of fetal age assessment based on BPD is dependent on gestational age.[28] between 12 and 26 weeks' gestation, the BPD inaccuracy may be due to that there are number of factors that may contribute to variation in the measurement as biologic variation, due to differences in maternal age, parity, pre pregnancy weight, geographic location, and specific population characteristics or may be due to technical factors. [29, 30]These justify our results that showed that in the relationship between BPD and gestational age, there were often significant differences in gestational age assignment. Femur length (FL) measurements may be used to accurately predict gestational age between 14 weeks gestation and term [31] most observers consider the accuracy of the FL and BPD measurements to be similar in the third trimester , the accuracy of gestational age prediction based on FL is greatest in the second trimester and least near term. Since the umbilical cord area is easy to be measured and has an accurate estimation of gestational age; it is recommended to be part of a routine ultrasound evaluation and as a routine part of prenatal care as it can greatly impact obstetric management and improve antepartum care. UCD measurement should prompt the physician to carefully evaluate the case whenever there is an incongruity between the observed and the normal values using ultrasound, as it is the modality of choice for the assessment of gestational age in the first and second and third trimester of pregnancy.

\section{Acknowledgements}

We sincerely thank the participants without whom the study would not have been feasible. The Sudan University of Science and Technology, College of Medical Radiological Science and El-Rabat Hospital are thankfully acknowledged.

\section{References}

[1] R. Brown, L .Di Luzio, and C. Gomes, K .Nicolaides. The umbilical artery pulsatility index in the first trimester: is there an association with increased nuchal translucency or chromosomal abnormality? Ultrasound Obstet Gynecol; 12: 244-7,(1998)

[2] M .Coppens, P.h. Loquet, M. Kollen, F. De Neubourg, P Buytaert. Longitudinal evaluation of utero placental and umbilical blood flow changes in normal early pregnancy. Ultrasound Obstet Gynecol; 7: 114-21,(1996)

[3] J.L .Alcazar, J .Rovira, M.L .Ruiz-Pérez, G .López-Garcia. Transvaginal color Doppler assessment of fetal circulation in normal early pregnancy. Fetal Diagn Ther; 12: 178-84,(1997)
[4] F .Qureshi, S.M .Jacques. Marked segmental thinning of the umbilical cord vessels. Arch Pathol Lab Med.;118:826-830,(1994)

[5] Y. Sun, S .Arbuckle, G. Hocking, V. Billso Umbilical cord stricture and intrauterine fetal death. Pediatr Pathol Lab Med.; 5:723-32. (1995)

[6] R.L .Deter, R.B. Harrist. Assessment of normal fetal growth .in: Chervenak FA, I saacson GC, Cambell S, editor. Ultrasound in Obstetrics and gynecology. Boston/Toronto/London: Little, Brown and Company;.p.361-85,(1993)

[7] R.L .Deter. Evaluation of quantitative obstetrical Ultrasound studies .In: Deter RL, Harrist RB, Birnholz JC, Hadlock FP, editor. Quantitative obstetrical Ultrasonography. New Yourk : Churchill Livingstone; p.15-30. (1986)

[8] F.P. Hadlock. Gestational age determination: Third Trimester .In: Chervenak FA, Isaacson GC, Campbell S, editor. Ultrasound in Obstetrics and gynecology. Boston/Toronto/London: Little, Brown and company;.p.311-20,(1993)

[9] L.M. Hill, D.M .Di Nofrio, D .Guzick. Sonographic determination of first Trimester umbilical cord length. J Clin Ultrasound; 22: 435-8,(1994)

[10] L. Raio, F .Ghezzi, E .Di Naro, M. Franchi, E. Maymon, M.D .Mueller, H .Brühwiler. Prenatal diagnosis of a lean umbilical cord: a simple marker for the fetus at risk of being small for gestational age at birth. Ultrasound Obstet Gynecol; 13: 176-80,(1999)

[11] E .Di Naro, F .Ghezzi, L .Raio, M .Franchi, V .D'Addario, G .Lanzillotti, H .Schneider. Umbilical vein blood flow in fetuses with normal and lean umbilical cord. Ultrasound Obstet Gynecol; 17: 224-8,(2001)

[12] J.F Bruch, O. Sibony, K .Benali, C .Challier, P. Blot, C Nessmann. Computerized microscope morphometry of umbilical vessels from pregnancies with intrauterine growth retardation and abnormal umbilical artery Doppler. Hum Pathol; 28: 1139-45,(1997)

[13] A .Weissman, P .Jakobi. Sonographic measurements of the umbilical cord in pregnancy complicated by gestational diabetes. J Ultrasound Med; 16: 691-4,(1997)

[14] R.K. Silver, S.L .Dooley, R.K. Tamura, R .Depp. Umbilical cord size and amniotic fluid volume in prolonged pregnancy. Am J Obstet Gynecol; 157: 716-20,(1987)

[15] R.C .Goodlin. Fetal dys maturity, 'lean cord', and fetal distress. Am J Obstet Gynecol; 56: 716,(1987)

[16] Robin B. Kalish, Frank Chervenak Sonographic Determination Of Gestational Age; Tmj, Vol. 59, No. 2,202-208,( 2009)

[17] R .Romero. Routine obstetric ultrasound. Ultrasound Obstet Gynecol; 3:303-7. (2003)

[18] P .Taipale, V .Hiilesmaa Predicting delivery date by ultrasound and last menstrual period in early gestation. Obstet Gynecol; 97:189-94. ( 2001)

[19] M.H .Hall, R.A Carr-Hill. The significance of uncertain gestation for obstetric outcome. Br J Obstet Gynaecol; 92:452-60,(1985) 
[20] L.M .Hellman, M .Kobayashi, Fillisti L et al: Growth and development of the human fetus prior to the twentieth week of gestation. Am J Obstet Gynecol 103: 789-800,(1969)

[21] P.C Jouppila: Length and depth of the uterus and the diameter of the gestation sac in normal gravidas during early pregnancy. Acta Obstet Gynecol Scand 50 (suppl): 29. (1971)

[22] A.B. Kurtz, R.J. Wapner, R.J. Kurtz et al. Analysis of biparietal diameter as an accurate indicator of gestational age. J Clin Ultrasound 8:319-326,(1980).

[23] F.P .Hadlock, R.L. Deter, R.B .Harrist, S.K. Park: Fetal biparietal diameter: A critical reevaluation of the relation to menstrual age by means of real-time ultrasound. J Ultrasound Med 1: 97-104. (1982)

[24] Hadlock FP, Deter RL, Harrist RB, Park SK: Fetal head circumference: Relation to menstrual age. AJR Am J Roentgenol;138(4): 649-653. (1982)

[25] F.P. Hadlock, R.L .Deter, R.B .Harrist, S.K. Park: fetal abdominal circumference as a predictor of menstrual age.
AJR Am J Roentgenol; 139: 367-370,(1982)

[26] P .Jeanty, F .Rodesch, D .Delbeke, J.E .Dumont: Estimation of gestational age from measurement of fetal long bones. $\mathrm{J}$ Ultrasound Med 3: 75-79,(1984)

[27] J.E .Rumm: The prediction of delivery date by ultrasonic measurement of fetal crown-rump length. $\mathrm{Br} \mathrm{J}$ Obstet Gynaecol 84: 1-5. ,(1977)

[28] M .Hepard, R.A .Filly: A standardized plane for biparietal diameter measurement. J Ultrasound Med 1: 145. (1982)

[29] R.M .Lunt, Chard L: Reproducibility of measurement of fetal biparietal diameter by ultrasonic cephalometry. J Obstet Gynaecol Br Commonw 81: 682-685(1974)

[30] J.M .Davison, T. Lind, V. Farr, T.A Whittingham: The limitations of ultrasonic fetal cephalometry. J Obstet Gynaecol Br Commonw 80: 769-775,(1981)

[31] P .Jeanty, F .Rodesch, D. Delbeke, J.E .Dumont: Estimation of gestational age from measurement of fetal long bones. $\mathrm{J}$ Ultrasound Med 3: 75-79(1984) 